\title{
HUBUNGAN PERILAKU PERSONAL HYGIENE DAN STATUS KECACINGAN DENGAN STATUS GIZI ANAK SEKOLAH DASAR DI WILAYAH KERJA PUSKESMAS II SUMBANG
}

\author{
Correlation Between Personal Hygiene Behavior, Helminthiasis Status, And \\ Nutritional Status Of Primary School In Puskesmas II Sumbang Work Area
}

\author{
Lida Arifin ${ }^{1}$ Dyah Umiyarni Purnamasari ${ }^{2}$ \\ ${ }^{1}$ Prodi Ilmu Gizi, Fakultas Ilmu-Ilmu Kesehatan, Universitas Jenderal Soedirman \\ ${ }^{2}$ Jurusan Kesehatan Masyarakat Fakultas Ilmu-Ilmu Kesehatan Unsoed
}

lidaarifin26@gmail.com,

\begin{abstract}
The purpose of this research is to determine relation between personal hygiene and status worm infection with nutritional status among primary children. This study design was observational analytic study with cross sectional approach. The sample were 51 children fourth grade 01 Banjarsari Kulon and 02 Banjarsari Wetan Primary School. Respondents with normal nutritional status 72\%. Respondents with good behavior personal hygiene 59\%. Respondents with positive helminthiasis status 53\%. Relation between personal hygiene and nutritional status was examined by chi square ( $p$ value $1.000>0.05)$. Relation between helminthiasis status and nutritional status $p$ value 0.425. Relation between personal hygiene and helminthiasis status $p$ value 0.625. There is no relation between the behavior of personal hygiene and nutritional status of school children in Puskesmas II Sumbang. There is no relation between helminthiasis status and nutritional status of school children in Puskesmas II Sumbang. There is no relation between personal hygiene and helminthiasis status.
\end{abstract}

Keywords: Personal hygiene, Helminthiasis status, Nutritional status

\begin{abstract}
Abstrak
Tujuan penelitian ini adalah untuk mengetahui hubungan antara personal higiene dan status infeksi cacing dengan status gizi pada anak-anak sekolah. Desain penelitian ini adalah penelitian analitik observasional dengan pendekatan cross sectional. Sampel adalah 51 anak kelas IV SD 01 Banjarsari Kulon dan SDN 02 Banjarsari Wetan. Responden dengan status gizi normal 72\%. Responden dengan perilaku baik kebersihan pribadi 59\%. Responden dengan status helminthiasis positif 53\%. Hubungan antara kebersihan pribadi dan status gizi diperiksa oleh chi square ( $\mathrm{p}$ value $1,000>0,05$ ). Hubungan antara status helminthiasis dan status gizi $\mathrm{p}$ value 0,425 . Hubungan antara personal hygiene dan status helminthiasis nilai $\mathrm{p} 0,625$. Tidak ada hubungan antara perilaku personal hygiene dengan status gizi anak sekolah di Puskesmas II Sumbang. Tidak ada hubungan antara status helminthiasis dan status gizi anak sekolah di Puskesmas II Sumbang. Tidak ada hubungan antara personal hygiene dan status helminthiasis.
\end{abstract}

Kata Kunci : Personal hygiene, status kecacingan, status gizi 


\section{PENDAHULUAN}

Tersedianya sumber daya manusia yang produktif ditentukan oleh kualitas sumber daya usia muda, yaitu anak sekolah dasar. Kurang gizi merupakan masalah gizi yang secara nyata berkaitan dengan pertumbuhan dan kemajuan suatu bangsa. Masalah gizi yang masih menjadi perhatian utama di negara berkembang adalah kurus (wasting) yang dapat mengganggu pertumbuhan dan perkembangan kognitif serta menurunkan produktivitas anak di sekolah (Caufield L.E et al, 2006).

Prevalensi kurus (menurut IMT/U) secara nasional berdasarkan hasil Riset Kesehatan Dasar (RISKESDAS) pada anak usia 5-12 tahun adalah 11,2 \%, dengan persentase $4 \%$ sangat kurus dan $7,2 \%$ kurus. Jawa tengah termasuk provinsi dengan prevalensi sangat kurus diatas nasional sebesar 4,6\%, sedangkan prevalensi kurus sebanyak 11,2\%. Kabupaten Banyumas mempunyai prevalensi status gizi anak usia 5-12 tahun menurut indeks IMT/U sebesar $3,9 \%$ sangat kurus dan $7,6 \%$ kurus (Riskesdas, 2013).

Seorang anak menjadi kurus disebabkan oleh dua hal penting, yaitu asupan makanan dan penyakit infeksi.
Apabila makanan anak kurang baik secara kuantitatif maupun kualitatif, badan tidak dapat membentuk struktur tubuh dengan sempurna, akibatnya pertumbuhan dan perkembangan terhambat. Penyakit infeksi merupakan salah satu penyakit yang banyak dijumpai pada anak - anak (Prawirohartono, 2009).

Salah satu jenis penyakit infeksi pada anak adalah infeksi kecacingan, yaitu infeksi yang disebabkan oleh kelompok cacing Soil-Transmitted Helminth. Secara kumulatif infeksi kecacingan dapat menghambat perkembangan fisik, mental, serta dapat menurunkan ketahanan tubuh sehingga rentan terserang penyakit lainnya (Depkes RI, 2006).

\section{METODE}

\section{Desain, Tempat dan waktu}

Penelitian ini menggunakan rancangan penelitian observasional analitik dengan pendekatan cross sectional. Penelitian dilakukan di SDN 02 Banjarsari Wetan dan SDN 01 Banjarsari Kulon Kecamatan Sumbang, Kabupaten Banyumas dari bulan Juni hingga Juli 2016.

\section{Jumlah dan cara pengambilan subjek}

Jumlah seluruh siswa SDN 01 Banjarsari Kulon dan SDN 02 Banjarsari Wetan sebanyak 328 siswa. Subjek dalam 
penelitian ini adalah siswa kelas IV sejumlah 51 responden. Tidak ada teknik pengambilan sampel dalam penelitian ini karena seluruh populasi dijadikan subjek penelitian.

\section{Analisis data}

Analisis univariat digunakan untuk mendeskripsikan variabel bebas (perilaku personal hygiene dan status kecacingan) serta variabel terikat (status gizi anak sekolah). Analisis bivariat yang digunakan adalah uji chi square yang digunakan untuk mengetahui hubungan antara variabel perilaku personal hygiene. status kecacingan, dan status gizi. Adanya hubungan yang signifikan dinyatakan dengan nilai $p<0,05$.

\section{HASIL DAN PEMBAHASAN}

\section{Gambaran Umum Tempat Penelitian}

Penelitian dilakukan di SDN 01 Banjarsari Kulon dan SDN 02 Banjarsari Wetan. Adapun gambaran umum dan fasilitas penunjang kesehatan dapat dilihat pada Tabel 1.

Tabel 1. Gambaran Umum dan Fasilitas Penunjang

\begin{tabular}{lcc}
\hline & SDN Banjarsari Kulon & SDN Banjarsari Wetan II \\
\hline Jumlah siswa & 222 Siswa & 106 Siswa \\
Jumlah guru & 11 Orang & 9 Orang \\
UKS & Ada & Ada \\
Kantin & Ada & Ada \\
Fasilitas cuci tangan & Tidak ada & Tidak ada \\
\hline
\end{tabular}

Sumber : data Primer Terolah, 2016

\section{Analisis Univariat}

Data yang diperoleh dari 51 responden, rata - rata usia responden yaitu 10 tahun 4 bulan, usia minimum responden 9 tahun 3 bulan dan usia maksimum responden 13 tahun 2 bulan. Data selengkapnya dapat dilihat pada Tabel 2.

Tabel 2. Karakteristik Responden Berdasarkan Usia

\begin{tabular}{lccc}
\hline & Usia & Jumlah \\
\cline { 2 - 4 } & & $\mathbf{N}$ & $\%$ \\
\hline 9 Tahun & 7 & 14 \\
10 Tahun & 31 & 61 \\
11 Tahun & 8 & 16 \\
12 Tahun & 1 & 2 \\
13 Tahun & 4 & 8 \\
\hline Total & 51 & 100 \\
\hline
\end{tabular}

Sumber : Data Primer Terolah, 2016 
Sebesar $51 \%$ responden berjenis dapat dilihat pada Tabel 3. kelamin laki - laki. Data selengkapnya

Tabel 3. Karakteristik Responden Berdasarkan Jenis Kelamin

\begin{tabular}{lcc}
\hline \multirow{2}{*}{ Jenis Kelamin } & \multicolumn{2}{c}{ Jumlah } \\
\cline { 2 - 3 } & $\mathbf{N}$ & \% \\
\hline Laki-laki & 26 & 51 \\
Perempuan & 25 & 49 \\
\hline Total & 51 & 100 \\
\hline
\end{tabular}

Sumber : Data Primer Terolah, 2016

Nilai IMT/U minimum sebesar -2.81, dan 0.4663). Selengkapnya dapat dilihat pada nilai maksimum sebesar 2.29. Rata-rata Tabel 4.

IMT/U dari seluruh responden sebesar (-

Tabel 4. Karakteristik Responden Berdasarkan Status Gizi

\begin{tabular}{|c|c|c|}
\hline \multirow{2}{*}{ Status Gizi } & \multicolumn{2}{|c|}{ Jumlah } \\
\hline & $\mathbf{N}$ & $\%$ \\
\hline Gemuk & 7 & 14 \\
\hline Normal & 37 & 72 \\
\hline Kurus & 7 & 14 \\
\hline Total & 51 & 100 \\
\hline
\end{tabular}

Sumber : Data Primer Terolah, 2016

Data yang didapatkan dari 51 Setiap perilaku yang dijawab benar responden, mayoritas responden diberikan skor 1, jika salah diberikan skor dikategorikan memiliki status gizi normal dengan persentase sebesar $72 \% \quad$ (37 0 . Total skor maksimal kuisioner perilaku personal hygiene sebesar 16. Berdasarkan responden).

Kategori responden berdasarkan perilaku personal hygiene dikategorikan menjadi 2, yaitu baik dan kurang baik. hasil analisis univariat total skor perilaku personal hygiene didapatkan mean sebesar 13.5490. Data selengkapnya terdapat pada Tabel

Tabel 5. Karakteristik Perilaku Personal Hygiene

\begin{tabular}{|c|c|c|c|c|c|c|}
\hline \multirow{3}{*}{ Jenis Kelamin } & \multicolumn{4}{|c|}{ Perilaku Personal Hygiene } & \multicolumn{2}{|c|}{ Total } \\
\hline & \multicolumn{2}{|c|}{ Baik } & \multicolumn{2}{|c|}{ Kurang Baik } & \multirow[b]{2}{*}{$\mathbf{N}$} & \multirow[b]{2}{*}{$\%$} \\
\hline & $\mathbf{N}$ & $\%$ & $\mathbf{N}$ & $\%$ & & \\
\hline Laki - laki & 12 & 46 & 14 & 54 & 26 & 100 \\
\hline Perempuan & 18 & 72 & 7 & 28 & 25 & 100 \\
\hline
\end{tabular}

Sumber: Data Primer Terolah, 2016 
Sebesar 59\% responden memiliki perilaku personal hygiene yang baik.
Adapun rincian pertanyaan kuisioner dan jawaban dapat dilihat pada Tabel 6 .

Tabel 6. Jawaban Kuisioner Perilaku Personal Hygiene

\begin{tabular}{|c|c|c|c|c|c|}
\hline \multirow{2}{*}{ No } & \multirow{2}{*}{ Pertanyaan } & \multicolumn{2}{|c|}{ Ya } & \multicolumn{2}{|c|}{ Tidak } \\
\hline & & $\mathbf{n}$ & $\%$ & $\mathbf{N}$ & $\%$ \\
\hline 1 & $\begin{array}{l}\text { Apakah setiap mau makan selalu mencuci } \\
\text { tangan terlebih dahulu? }\end{array}$ & 51 & $100 \%$ & - & - \\
\hline & $\begin{array}{l}\text { Apakah mencuci tangan menggunakan } \\
\text { sabun? }\end{array}$ & 50 & $98 \%$ & 1 & $2 \%$ \\
\hline & $\begin{array}{l}\text { Apakah setelah berolahragaselalu } \\
\text { mencuci tangan? }\end{array}$ & 35 & $69 \%$ & 16 & $31 \%$ \\
\hline & $\begin{array}{l}\text { Apakah setelah bermain langsung mencuci } \\
\text { tangan? }\end{array}$ & 40 & $78 \%$ & 11 & $22 \%$ \\
\hline & $\begin{array}{l}\text { Apakah sebelum makan jajan selalu } \\
\text { mencuci tangan dulu? }\end{array}$ & 47 & $92 \%$ & 4 & $8 \%$ \\
\hline 6 & $\begin{array}{l}\text { Apakah setelah buang air besar adik } \\
\text { mencuci tangan? }\end{array}$ & 43 & $84 \%$ & 8 & $16 \%$ \\
\hline 7 & $\begin{array}{l}\text { Apakah setelah buang air besar mencuci } \\
\text { tangan menggunakan sabun? }\end{array}$ & 47 & $92 \%$ & 4 & $8 \%$ \\
\hline 8 & Apakah selalu menjaga kebersihan kuku? & 47 & $92 \%$ & 4 & $8 \%$ \\
\hline & $\begin{array}{l}\text { Apakah ada pengawasan dari Bapak/Ibu } \\
\text { tentang kebersihan kuku? }\end{array}$ & 36 & $71 \%$ & 15 & $29 \%$ \\
\hline 10 & $\begin{array}{l}\text { Apakah selalu memotong kuku } 2 \text { minggu } \\
\text { sekali? }\end{array}$ & 28 & $55 \%$ & 23 & $45 \%$ \\
\hline 11 & $\begin{array}{l}\text { Apakah sering buang air besar di jamban/ } \\
\text { WC? }\end{array}$ & 36 & $71 \%$ & 15 & $29 \%$ \\
\hline 12 & Apakah BAB di kebun/sungai? & 46 & $90 \%$ & 5 & $10 \%$ \\
\hline & $\begin{array}{l}\text { Apakah jamban dibersihkan minimal } \\
\text { seminggu sekali? }\end{array}$ & 38 & $75 \%$ & 13 & $25 \%$ \\
\hline & $\begin{array}{l}\text { Apakah adik setiap bermain di luar rumah } \\
\text { Menggunakan alas kaki (sandal/sepatu)? }\end{array}$ & 45 & $88 \%$ & 6 & $12 \%$ \\
\hline & Apakah keramas seminggu sekali?* & 51 & $100 \%$ & - & - \\
\hline 16 & Apakah mandi 2x sehari? & 51 & $100 \%$ & - & - \\
\hline
\end{tabular}

*pertanyaan negatif

Data yang didapatkan dari 51 responden menunjukkan bahwa pertanyaan kuisioner perilaku personal hygiene yang dijawab benar oleh seluruh responden adalah pertanyaan nomor 1 , nomor 15, dan nomor 16.

\section{Pemeriksaan}

dilakukan di Laboratorium Epidemiologi Universitas Jenderal Soedirman dengan sampel feses siswa kelas IV SDN Banjarsari Kulon I dan Banjarsari Wetan II. Metode yang digunakan ialah menggunakan metode apung. Data selengkapnya dapat dilihat pada Tabel 7. 
Tabel 7 Distribusi Responden Berdasarkan Status Kecacingan

\begin{tabular}{lcc}
\hline \multirow{2}{*}{ Status Kecacingan } & \multicolumn{2}{c}{ Jumlah } \\
\cline { 2 - 3 } & $\mathbf{N}$ & $\mathbf{\%}$ \\
\hline Positif & 27 & 53 \\
Negatif & 24 & 47 \\
\hline Total & 51 & 100 \\
\hline Sumber: Data Primer Terolah, 2016 & &
\end{tabular}

Hasil pemeriksaan menunjukkan kecacingan.

bahwa sebesar 53\% responden positif

\section{Analisis Bivariat}

Hubungan Perilaku Personal Hygiene dengan Status Gizi Anak Sekolah

Variabel perilaku personal hygiene dan status gizi diuji menggunakan uji chi square pada software SPSS 16.00. Hasil uji dapat dilihat pada Tabel

8.

Tabel 8. Hasil Uji Chi Square Perilaku Personal Hygiene dan Status Gizi

\begin{tabular}{|c|c|c|c|c|c|c|c|}
\hline \multirow{3}{*}{$\begin{array}{c}\text { Perilaku personal } \\
\text { hygiene }\end{array}$} & \multicolumn{4}{|c|}{ Status Gizi } & \multirow{2}{*}{\multicolumn{2}{|c|}{ Total }} & \multirow{3}{*}{ p value } \\
\hline & \multicolumn{2}{|c|}{ Normal } & \multicolumn{2}{|l|}{ Kurus } & & & \\
\hline & $\mathbf{n}$ & $\%$ & $\mathbf{n}$ & $\%$ & $\mathbf{n}$ & $\%$ & \\
\hline Baik & 26 & 87 & 4 & 13 & 30 & 100 & $10 \cap 0$ \\
\hline Kurang Baik & 18 & 86 & 3 & 14 & 21 & 100 & 1.000 \\
\hline
\end{tabular}

Sumber : Data Primer Terolah, 2016

Berdasarkan hasil uji chi square didapatkan nilai fisher exact sebesar $1.000(>\quad 0.05)$ sehingga dapat disimpulkan bahwa tidak ada hubungan perilaku personal hygiene dengan status gizi pada anak sekolah. Analisis subgrup antara perilaku personal hygiene dan status gizi anak sekolah normal dapat dilihat pada Tabel 9.

Tabel 9. Analisis Subgrup Perilaku Personal Hygiene dengan Status Gizi Anak Sekolah Normal

\begin{tabular}{llcc}
\hline & & Status Gizi Normal \\
& & $\mathbf{N}$ & $\boldsymbol{\%}$ \\
\hline \multirow{2}{*}{ Perilaku Personal Hygiene } & Baik & 26 & 59 \\
& Kurang baik & 18 & 41 \\
\hline Total & & 44 & 100 \\
\hline Sumber : Data Primer Terolah, 2016 & &
\end{tabular}

$59 \%$ responden dengan status gizi normal memiliki perilaku personal hygiene yang baik. Analisis subgrup antara perilaku personal hygiene dan anak dengan status gizi kurus dapat dilihat pada Tabel 10. 
Tabel 10. Analisis Subgrup Perilaku Personal Hygiene dengan Status Gizi Anak Sekolah Kurus

\begin{tabular}{llrc}
\hline & & \multicolumn{2}{c}{ Status Gizi Kurus } \\
\cline { 3 - 4 } & & $\mathbf{N}$ & $\%$ \\
\hline \multirow{2}{*}{ Perilaku Personal Hygiene } & Baik & 4 & 57 \\
& Kurang baik & 3 & 43 \\
\hline Total & & 7 & 100 \\
\hline
\end{tabular}

Sumber : Data Primer Terolah, 2016

Sebesar 57\% responden dengan status gizi kurus memiliki perilaku personal hygiene yang baik. Penelitian ini mengungkapkan bahwa tidak ada hubungan antara perilaku personal hygiene dan status gizi pada anak sekolah. Walaupun demikian, ada kecenderungan bahwa responden dengan perilaku personal hygiene yang baik memilliki status gizi normal, dibuktikan dengan hasil penelitian yang menunjukkan jumlah responden dengan perilaku personal hygiene yang baik dan status gizi normal sebesar 59\% sedangkan responden dengan perilaku personal hygiene yang baik dan status gizi kurus sebesar 57\%. Penyebab langsung yang dapat mempengaruhi status gizi adalah asupan makanan dan penyakit infeksi, sedangkan penyebab tidak langsung yang mempengaruhi status gizi adalah pola ketahanan pangan, pola pengasuhan, pelayanan kesehatan, dan sanitasi lingkungan (Sokirman, 2000).
Seseorang dengan perilaku personal hygiene baik namun konsumsi makanan kurang baik akan lebih mudah terpapar infeksi dan menyebabkan menurunnya status gizi (Soekirman, 2000). Vivas et al (2010) mengemukakan bahwa alasan yang mempengaruhi perilaku personal hygiene pada anak sekolah adalah ketersediaan fasilitas dan sanitasi lingkungan. Kurangnya fasilitas cuci tangan menggunakan air bersih dan sabun memberikan dampak yang besar terhadap perilaku mencuci tangan. Terbatasnya jumlah air bersih membuat masyarakat lebih banyak memanfaatkan air untuk keperluan minum, memasak, dan mencuci pakaian, dibandingkan untuk mandi dan keramas. Faktor lain yang mempengaruhi perilaku personal hygiene adalah pola pengasuhan. Namun keterbatasan penelitian ini adalah tidak mengamati lebih lanjut tentang pola pengasuhan anak. 
Hubungan Status Kecacingan dengan Status Gizi Anak Sekolah

Variabel status kecacingan dan status gizi diuji menggunakan uji chi square pada software SPSS 16.00 dengan hasil pada Tabel 11.

Tabel 11. Hasil Uji Chi Square Hubungan Status Kecacingan dan Status Gizi

\begin{tabular}{|c|c|c|c|c|c|c|}
\hline \multirow{3}{*}{ Status Kecacingan } & \multicolumn{3}{|c|}{$\begin{array}{l}\text { Status Gizi } \\
\end{array}$} & \multirow{2}{*}{\multicolumn{2}{|c|}{ Total }} & \multirow{3}{*}{ p value } \\
\hline & \multicolumn{2}{|c|}{ Normal } & \multirow{2}{*}{$\frac{\text { Kurus }}{\text { n \% }}$} & & & \\
\hline & $\mathbf{N}$ & $\%$ & & $\mathrm{n}$ & $\%$ & \\
\hline Negatif & 22 & 92 & 28 & 24 & 100 & 0425 \\
\hline Positif & 22 & 81 & 519 & 27 & 100 & $0.42 J$ \\
\hline
\end{tabular}

Berdasarkan hasil uji chi square didapatkan nilai fisher exact sebesar 0.425 (> 0.05) sehingga disimpulkan bahwa tidak ada hubungan antara status kecacingan dengan status gizi pada anak sekolah. Analisis subgrup antara status kecacingan dengan status gizi dapat dilihat dari Tabel 12 .

Tabel 12. Analisis Subgrup Status Kecacingan dengan Status Gizi Anak Sekolah Normal

\begin{tabular}{llcc}
\hline & & \multicolumn{2}{c}{ Status Gizi Normal } \\
\cline { 3 - 4 } & & $\mathbf{N}$ & $\mathbf{\%}$ \\
\hline \multirow{2}{*}{ Status Kecacingan } & Negatif & 22 & 50 \\
& Positif & 22 & 50 \\
\hline Total & & 44 & 100 \\
\hline
\end{tabular}

Sumber : Data Primer Terolah, 2016

Masing - masing responden dengan status kecacingan positif dan negatif persentasenya sebesar $50 \%$ pada kategori status gizi normal. Tabulasi silang status kecacingan dan status gizi pada anak sekolah kurus dapat dilihat pada Tabel 13.

Tabel 13. Analisis Subgrup Status Kecacingan dengan Status Gizi Anak Sekolah Kurus

\begin{tabular}{llcc}
\hline & & \multicolumn{2}{c}{ Status Gizi Kurus } \\
\cline { 3 - 4 } & & \multicolumn{2}{c}{$\mathbf{N}$} \\
\hline \multirow{2}{*}{ Status Kecacingan } & Negatif & 2 & 29 \\
& Positif & 5 & 71 \\
\hline Total & & 7 & 100 \\
\hline
\end{tabular}

Sumber : Data Primer Terolah, 2016

Sebesar $71 \%$ responden pada kategori status gizi kurus memiliki status kecacingan positif. Penelitian ini mengungkapkan bahwa tidak ada hubungan antara status kecacingan dan status gizi pada anak sekolah. Namun 
berdasarkan data yang diperoleh, ada kecenderungan bahwa responden dengan status kecacingan negatif dan memiliki status gizi normal persentasenya lebih tinggi dibandingkan dengan responden dengan status gizi kurus. Hal ini dibuktikan bahwa persentase responden dengan status kecacingan negatif dan status gizi normal sebesar 50\%, sedangkan responden dengan kecacingan negatif dan status gizi kurus sebesar $29 \%$.

Tidak adanya hubungan antara status kecacingan terhadap status gizi dipengaruhi oleh tingkat keparahan infeksi dan kuantitas larva cacing yang ada di dalam tubuh manusia. Setiap manusia mempunyai respon tubuh yang berbeda terhadap infeksi. Meskipun persentase responden yang terinfeksi tinggi, intensitas infeksi (jumlah cacing dalam perut) setiap orang berbeda (Kemenkes, 2006).

Hubungan antara Perilaku Personal Hygiene dengan Status Kecacingan

Variabel perilaku personal hygiene dan status kecacingan diuji menggunakan uji chi square pada software SPSS 16.00 dengan hasil pada Tabel 14.

Tabel 14. Hasil Uji Chi Square Perilaku Personal Hygiene dan Status Kecacingan

\begin{tabular}{|c|c|c|c|c|c|c|c|}
\hline \multirow{3}{*}{ Perilaku personal hygiene } & \multicolumn{4}{|c|}{ Status Kecacingan } & \multirow{2}{*}{\multicolumn{2}{|c|}{ Total }} & \multirow{3}{*}{$p$ value } \\
\hline & \multicolumn{2}{|c|}{ Negatif } & \multicolumn{2}{|c|}{ Positif } & & & \\
\hline & $\mathbf{n}$ & $\%$ & $n$ & $\%$ & n & $\%$ & \\
\hline Baik & 15 & 50 & 15 & 50 & 30 & 100 & 0615 \\
\hline Kurang Baik & 9 & 43 & 12 & 57 & 21 & 100 & 0.015 \\
\hline
\end{tabular}

Sumber : Data Primer Terolah, 2016

Hasil uji chi square dengan variabel perilaku personal hygiene dan status kecacingan didapatkan nilai fisher exact sebesar 0.615 (lebih besar dari 0.05) sehingga dapat disimpulkan tidak ada hubungan antara perilaku personal hygiene dan status kecacingan. Analisis subgrup antara perilaku personal hygiene dan status kecacingan positif dapat dilihat pada Tabel 15.

Tabel 15. Analisis Subgrup Perilaku Personal Hygiene dan Status Kecacingan Positif

\begin{tabular}{|c|c|c|c|}
\hline & & Positif & \\
\hline & & $\mathbf{N}$ & $\%$ \\
\hline Perilaku Personal Hvoiene & Baik & 15 & 56 \\
\hline Perilaku Personal Hygıene & Kurang baik & 12 & 44 \\
\hline Total & & 27 & 100 \\
\hline Sumber : Data Primer Terolah, & & & \\
\hline & & kecacingan & positif \\
\hline
\end{tabular}


Analisis subgrup antara perilaku personal dapat dilihat pada Tabel 16.

hygiene dan status kecacingan negatif

Tabel 16. Analisis Subgrup Perilaku Personal Hygiene dan Status Kecacingan Negatif

\begin{tabular}{llcc}
\hline & & \multicolumn{2}{c}{ Negatif } \\
\cline { 3 - 4 } & & \multicolumn{2}{c}{ N } \\
\hline \multirow{2}{*}{ Perilaku Personal Hygiene } & Baik & 15 & 63 \\
& Kurang baik & 9 & 38 \\
\hline Total & & 24 & 100 \\
\hline Sumber : Data Primer Terolah, 2016 & &
\end{tabular}

Sumber : Data Primer Terolah, 2016

Sebesar $63 \%$ responden dengan status kecacingan negatif memiliki perilaku personal hygiene yang baik. Hasil berbeda diperlihatkan oleh penelitian Scolari et al (2000) yang mengungkapkan bahwa prevalensi anak anak yang terinfeksi cacing Soil Transmitted Helminth di daerah pedesaan lebih besar dibandingkan dengan anak anak di daerah perkotaan. Strunz et al (2014) mengungkapkan bahwa secara umum akses air, personal hygiene, dan sanitasi yang baik berhubungan dengan penurunan infeksi kecacingan. Sebesar $33 \%$ penurunan infeksi kecacingan terjadi pada kelompok yang diberi perlakuan untuk melakukan perilaku personal hygiene yang baik.

$$
\text { Beberapa faktor yang }
$$

dimungkinkan menjadi penyebab tidak adanya hubungan perilaku personal hygiene dan status kecacingan pada penelitian ini adalah data yang kurang sensitif mengenai perilaku personal hygiene dan jawaban kusioner yang mengandalkan daya ingat responden. Jumlah subjek penelitian yang kurang dari perhitungan minimal sampel menyebabkan variasi data dan hubungan menjadi tidak signifikan. Faktor pengganggu lain adalah status sosial ekonomi, gender, dan umur subjek penelitian (Strunz, 2014).

\section{SIMPULAN DAN SARAN}

Penelitian ini mengemukakan bahwa tidak ada hubungan antara status kecacingan dengan status gizi pada anak sekolah di wilayah kerja Puskesmas II Sumbang. Tidak ada hubungan antara perilaku personal hygiene dan status kecacingan pada anak sekolah dasar di wilayah kerja Puskesmas II Sumbang.

Saran dalam upaya menurunkan prevalensi kecacingan diharapkan perlu dibiasakan perilaku personal hygiene yang baik pada anak sekolah dasar 
terutama mencuci tangan dan kebersihan kuku dikarenakan hasil kuisioner menunjukkan persentase perilaku personal hygiene kebersihan kuku (55\% responden) dan mencuci tangan setelah melakukan aktivitas (69\% responden) masih rendah. Perlu dilakukan pencegahan infeksi kecacingan dengan penerapan personal hygiene yang baik dan meminum obat cacing secara teratur untuk memutus rantai cacing di dalam tubuh.

\section{DAFTAR PUSTAKA}

Adiningsih S. 2010. Waspadai Gizi Balita Anda. Elex Media Komputindo. Jakarta. Almatsier S. 2003. Prinsip Dasar Ilmu Gizi. Gramedia Pustaka Utama. Jakarta.

Anggraini F. 2003. Faktor-Faktor yang Berhubungan dengan Status Gizi Siswa Sekolah Dasar di Kecamatan Pancoran Jakarta Selatan. Skripsi. Fakultas Kesehatan Masyarakat Universitas Indonesia.

Badan Penelitian dan Pengembangan Kesehatan. 2013. Riset Kesehatan Dasar (Riskesdas 2013). Kementerian Kesehatan Republik Indonesia. Jakarta.

Caufield LE, Richard SA, dan Rivera J. 2016. Stunting, Wasting, and Micronutrient Deficiency Disorder. In Jamison DT, Breman JG, Measham AR, Alleyne G, Cleaso M, Evans $\mathrm{DB}$, et al Editors. Disease
Control Priorities in Developing Countries. 2nd ed, The World Bank and Oxford University Press, New York.

Departemen Kesehatan RI. 2006. Keputusan Menteri Kesehatan Republik Indonesia tentang Pedoman Pengendalian Kecacingan. Kementerian Kesehatan Republik Indonesia. Jakarta.

Gupte S. 2004. Panduan Keperawatan Anak. Pustaka Populer Obor. Jakarta.

Scolari C, Torti C, Beltrame A, Matteelli A, Castelli F, Gulletta M, Ribas, M, Morana S, dan Urbani C. 2000. Prevalence and Distribution of Soil-Transmitted Helminth (STH) Infections in Urban and Indigenous Schoolchildren in Ortigueira State of Parana Brasil : Implications for Control. Tropical Medicine and International Journal Vol.5. University of Brescia. Italy.

Soekirman. 2000. Ilmu Gizi dan Aplikasinya. Direktorat Jenderal Pendidikan Tinggi Departemen Pendidikan Nasional. Jakarta.

Strunz E, Addiss D, Stocks M, Ogden S, Utzinger S, dan Freeman M. 2014. Water, Sanitation, Hygiene, and Soil-Transmitted Helminth Infection : a Systematic Review and MetaAnalysis. PLOS Medicine Journal. United States.

UNICEF. 1998. The State of The World's Children 1998. Oxford: Oxford University Press. 
J.Gipas, Mei 2018, Volume 2 Nomor 1 ISSN 2599-0152 eISSN 2599-2465

http://jos.unsoed.ac.id/index.php/jgps

Vivas A, Gelaye B, Abozet NKA,

School Children in Angolela Berhane Y, William M. 2010. Ethiopia. Journal. USA.

Knowledge, Attitudes, and

Practice of Hygiene Among 